\title{
The Influence of iso-Butanol Addition to the Chemistry of Premixed 1,3-Butadiene Flames
}

\author{
M. Braun-Unkhoff, ${ }^{1 *}$ N. Hansen, ${ }^{2 *}$ T. Methling, ${ }^{1}$ K. Moshammer, ${ }^{2}$ B. Yang $^{3}$ \\ ${ }^{1}$ German Aerospace Center (DLR), Institute of Combustion Technology, 70569 Stuttgart, \\ Germany \\ ${ }^{2}$ Combustion Research Facility, Sandia National Laboratories, Livermore, CA 94551, USA \\ ${ }^{3}$ Center for Combustion Energy and Department of Thermal Engineering, Tsinghua University, \\ Beijing, 100084, China \\ to be submitted to: \\ $36^{\text {th }}$ International Symposium on Combustion \\ "Laminar Flames" Colloquium
}

\begin{tabular}{lr}
\multicolumn{1}{c}{$\quad$ Word Count (MS Word) } & \\
Abstract: & 177 \\
Introduction: & 433 \\
Experimental Procedures: & 569 \\
Combustion Chemistry Modeling: & 185 \\
Results and Discussion: & 1594 \\
Conclusions: & 263 \\
Acknowledgements: & 137 \\
35 References: & 647 \\
1 Table: & 53 \\
9 Figures: 176+199+383+241+151+304+202+154+376 & 2286 \\
Total Words (excluding abstract): & $\mathbf{6 1 6 7}$
\end{tabular}

Supplementary Material is available.

\footnotetext{
* Corresponding authors:

email: nhansen@sandia.gov (NH) and marina.braun-unkhoff@dlr.de (MBU)
} 


\section{Abstract:}

Chemical structures of three low-pressure premixed flames of 1,3-butadiene/i-butanol mixtures with different ratios of 1,3-butadiene and $i$-butanol were investigated experimentally with flamesampling molecular-beam mass spectrometry and numerically by chemically detailed modeling. Partially isomer-resolved mole fraction profiles of approximately 70 components per flame were determined using the well-established single-photon ionization technique via easily tunable synchrotron-generated vacuum-ultraviolet photons. The used chemical-kinetic reaction model is based on the work of Hansen et al. [Proc. Combust. Inst. 35 (2015) 771-778] of complementary 1,3-butadiene/ $n$-butanol mixture flames. Within the present study, the reaction model has been significantly updated and simultaneously extended, to include the high-temperature oxidation chemistry of $i$-butanol. It is shown, by referring to both experimental and modeling results, that the concentration of benzene depends on the amount of 1,3-butadiene in the fuel mixture, indicating that $i$-butanol chemistry is not adding significantly towards aromatic ring formation. Trends in the concentration of other intermediates can also be largely predicted based on the established oxidation of 1,3-butadiene and $i$-butanol, thus revealing no detectible cross-linkages between the intermediate pools of the individual fuel components.

Keywords: 1,3-butadiene; $i$-butanol; biofuel; combustion; modeling 


\section{Introduction}

The combustion chemistry of alcohols remains an interesting research topic $[1,2]$. Especially, the larger alcohols, e.g., butanols and pentanols, recently received a lot of attention in the combustion community because their physical-chemical properties make them attractive as alternative fuels [2-6]. But given the fact that alcohols are likely to enter the fuel market mainly as additive to conventional petroleum-based fuels, it is important to understand the combustion chemistry in flames of hydrocarbon/alcohol blends. To this end, we have performed an experimental and modeling study of the combustion chemistry in flames fueled by blends of 1,3-butadiene $\left(\mathrm{CH}_{2} \mathrm{CHCHCH}_{2}\right)$ with $i$-butanol $\left[\left(\mathrm{CH}_{3}\right)_{2} \mathrm{CHCH}_{2} \mathrm{OH}\right]$. These components are interesting choices because 1,3-butadiene represents a small linear hydrocarbon fuel with $\mathrm{C}=\mathrm{C}$ double bonds; it has been used widely in many flame studies as a model compound for di-enes and especially the readily formation of the $\mathrm{C}_{4} \mathrm{H}_{5}$ radicals makes it an interesting fuel for studying their importance on the aromatics formation (see Ref. [7] for a summary). $i$-Butanol has interesting properties that make it an attractive additive to or replacement for petroleum-based hydrocarbon fuels, for example, it has a higher energy density and a higher cetane number than the commonly considered ethanol [2].

In this work, we report new experimental data in the form of partially isomer-resolved species mole fraction profiles in low-pressure premixed flames fueled by three different 1,3-butadiene/i-butanol mixtures and performed modeling calculations to provide insights into the effect of alcohol addition to the species pool and the formation of benzene. This work is a continuation of our earlier work, in which we have studied the effect of $n$-butanol $\left(\mathrm{CH}_{3} \mathrm{CH}_{2} \mathrm{CH}_{2} \mathrm{CH}_{2} \mathrm{OH}\right)$, an isomer of $i$-butanol, on the formation of the "first aromatic ring", i.e., benzene, in a 1,3-butadiene flame [8]. It was found that benzene formation is proportional to the 
amount of 1,3-butadiene in the fuel mixture. This observation was traced back to the efficient formation of the precursor molecules propargyl $\left(\mathrm{C}_{3} \mathrm{H}_{3}\right)$ and $i-\mathrm{C}_{4} \mathrm{H}_{5}$ from 1,3-butadiene while none of the commonly considered benzene precursors $\left(\mathrm{C}_{3} \mathrm{H}_{3}, \mathrm{C}_{3} \mathrm{H}_{5}\right.$, or $\left.i-\mathrm{C}_{4} \mathrm{H}_{5}\right)$ are effectively formed during $n$-butanol oxidation.

We have now substantially updated the previously used model [8] and simultaneously extended it to include the high-temperature oxidation chemistry of $i$-butanol. Updates include the implementation of the fulvene chemistry, which is expected to be important in benzene formation processes $[9,10]$, and of the enol chemistry, which can be important in the oxidation processes of alcohols [11, 12]. The improved capabilities of the updated model were tested against the newly determined chemical structures of the 1,3-butadiene/i-butanol flames; a reaction path analysis provides detailed insights into the combustion chemistry of such mixture flames.

\section{Experimental Procedures}

The detailed conditions of the three premixed low-pressure flames studied in this work are given in Table 1. The flames were stabilized with a constant $\mathrm{C} / \mathrm{O}$ ratio of 0.5 on a watercooled stainless steel McKenna burner at a pressure of 30 Torr. Although the constant $\mathrm{C} / \mathrm{O}$ ratio leads to slightly different flame stoichiometries, the conditions were chosen to allow for a simpler comparison to the previously published complementary 1,3-butadiene/n-butanol mixture flames [8]. The fuel composition changes from 75\% 1,3-butadiene (Flame 1), to 50\% (Flame 2), and $25 \%$ (Flame 3). The gas flows were measured with calibrated flow meters. The flow of $i$ butanol was measured with a syringe pump, before it was vaporized and added quantitatively to the gas stream. 
Table 1: Flame Conditions

\begin{tabular}{|c|c|c|c|c|c|c|c|}
\hline & \multirow[t]{2}{*}{$\varphi^{\text {a) }}$} & \multirow[b]{2}{*}{$\mathrm{Ar}$} & \multicolumn{3}{|c|}{ Cold Gas Composition (\%) } & \multirow{2}{*}{$\begin{array}{l}\text { Pressure } \\
\text { (Torr) }\end{array}$} & \multirow{2}{*}{$\begin{array}{c}\text { Cold Gas } \\
\text { Velocity }\left(\mathrm{cm} \mathrm{s}^{-1}\right)\end{array}$} \\
\hline & & & 1,3-Butadiene & $i$-Butanol & $\mathrm{O}_{2}$ & & \\
\hline Flame 1 & 1.45 & 50.0 & 7.7 & 2.6 & 39.7 & 30 & 65.1 \\
\hline Flame 2 & 1.53 & 50.0 & 5.3 & 5.3 & 39.5 & 30 & 65.1 \\
\hline Flame 3 & 1.62 & 50.0 & 2.7 & 8.1 & 39.2 & 30 & 65.1 \\
\hline
\end{tabular}

${ }^{\text {a) }}$ Fuel equivalence ratio / stoichiometry

The chemical structures of these flames were investigated by flame-sampling molecularbeam mass spectrometry. Details of the set-up have been described previously [13-15] and only a short description is provided in the next paragraphs. We used a quartz probe with an opening of about $300 \mu \mathrm{m}$ in diameter to sample gases from various flame positions via a differentially pumped system into the ionization region of a custom-built reflectron time-of-flight mass spectrometer. Ionization of the sampled flame constituents was achieved with a quasi-continuous beam of synchrotron-generated vacuum-ultraviolet photons in the energy range of 8-17 eV. This part of the work was performed at the Chemical Dynamics Beamline of the Advanced Light Source of the Lawrence Berkeley National Laboratory [16]. The mass resolution of the reflectron time-of-flight mass spectrometer is $m / \Delta m \sim 3500$, thus allowing for a separation of the oxygenated and hydrocarbon species based on their exact mass in the mass range of interest. The detection limit is in the order of $1 \mathrm{ppm}$.

Flame components were identified based on the mass-to-charge $(\mathrm{m} / \mathrm{z})$ ratio and photoionization efficiency (PIE) curves, as outlined previously [13-15, 17], and subsequently mass spectra were recorded as function of distance from the burner surface at fifteen different photon energies in order to provide the most reliable isomer-resolved mole fraction profiles. The 
position of the burner assembly with regards to the fixed quartz probe was adjusted with a computer controlled stepper motor and the accuracy is assumed to be within $\pm 0.5 \mathrm{~mm}$. Data analysis procedures are described in Ref. [18]. Mass discrimination factors were determined from cold-gas measurements of calibrated gas mixtures, the photon flux was measured with a calibrated photodiode, and the photoionization cross section were taken from the USTC-based data base [19].

A detailed description of the expected uncertainties is provided in Ref. [15]. In short, we expect the mole fraction profiles of the major species to be within $\pm 20 \%$ and somewhat larger for the intermediate species, depending on the isomeric composition at the respected $\mathrm{m} / \mathrm{z}$ ratio and/or the reliability of the used photoionization cross sections. About 70 flame components were quantified for each flame and the data are available in the Supplementary Material.

Unperturbed temperature profiles of the flames were measured using OH LIF as described in Ref. [20] and used as input for the flame modeling calculations. The uncertainty is expected to be $\pm 150 \mathrm{~K}$ in the postflame and reaction zone and somewhat larger in the preheat zone because of the lower $\mathrm{OH}$ concentrations and steeper gradients. Given the uncertainty of the temperature profiles, it is important to remember that Dooley et al. have shown that even large changes to the temperature profile are likely to not lead to any changes of the mechanistic conclusions [21].

\section{Combustion Chemistry Modeling}

For this study, a sub-model describing the oxidation of $i$-butanol was added to the DLR reaction mechanism which was recently used to model the oxidation of 1,3-butadiene/n-butanol blends [8]. It is based on earlier work on propene [22] and cyclopentene [23] low-pressure 
flames and includes soot precursors and aromatics [24-26]. The $i$-butanol oxidation sub-model was gathered from Sarathy et al. [2]. Furthermore, the fulvene chemistry was added as described in Ref. [27]. In total, 70 species and 273 reactions were newly incorporated. The updated chemical-kinetic reaction mechanism consists of 286 species and 1396 elementary reactions. The mechanism (including thermos and transport data) is available in the Supplementary Material.

Computer simulations of the isobaric burner-stabilized flames were performed with the open-source software Cantera [28] using the experimental temperature profiles (without any shifts). In addition, initial mass flow rates and composition of the educts as well as the burner's diameter served as further input data. For the simulations, the multi-component diffusion model and thermo-diffusion were considered. For the involved species, transport data were taken from Ref. [29] and thermodynamical data from Ref. [30].

\section{Results and Discussion}

\subsection{Global Chemical Flame Structures}

To provide an overview of the global chemical flame structures and to assess the model's predictive capabilities, we begin the discussion presenting experimental and modeled mole fraction profiles of the major species $\left(\mathrm{H}_{2}, \mathrm{H}_{2} \mathrm{O}, \mathrm{CO}, \mathrm{O}_{2}, \mathrm{Ar}, \mathrm{CO}_{2}, 1,3-\mathrm{C}_{4} \mathrm{H}_{6}, i-\mathrm{C}_{4} \mathrm{H}_{9} \mathrm{OH}\right)$. As shown exemplarily in Fig. 1 for Flame 2, the agreement is very good between the experimental and modeled main species mole fraction profiles. Similar levels of agreement are also achieved for the other two flames. For $i$-butanol, the rate of consumption appears to be slightly overpredicted. However, considering the measurement uncertainties close to the burner surface due to probe perturbation and large gradients in the temperature profiles, the updated mechanism is capable of predicting the global features of the 1,3-butadiene/ $i$-butanol mixtures flames. 


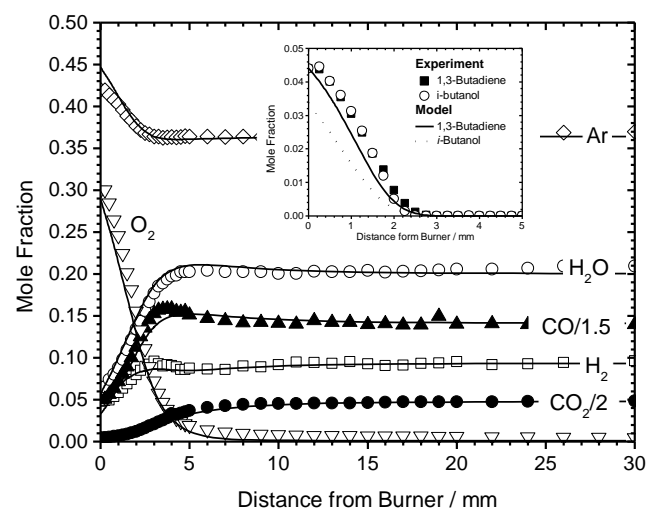

Figure 1: Mole fraction profiles of the main species $\left(\mathrm{H}_{2}, \mathrm{H}_{2} \mathrm{O}, \mathrm{CO}, \mathrm{O}_{2}, \mathrm{Ar}, \mathrm{CO}_{2}, 1,3-\mathrm{C}_{4} \mathrm{H}_{6}\right.$, and $\left.i-\mathrm{C}_{4} \mathrm{H}_{9} \mathrm{OH}\right)$ as function of the distance from the burner. Experimental data are shown as symbols and model results as lines.

\subsection{Fuel Consumptions and Intermediate Species Pools}

1,3-Butadiene and $i$-butanol flames have been studied before (see Refs. [31, 32]) and their individual consumption pathways to $\mathrm{C}_{3}$ and $\mathrm{C}_{4}$ intermediates are outlined in Fig. 2. This simplified sketch serves as a basis for the following discussion on the influence of $i$-butanol addition on the intermediate species pool in these mixture flames. 


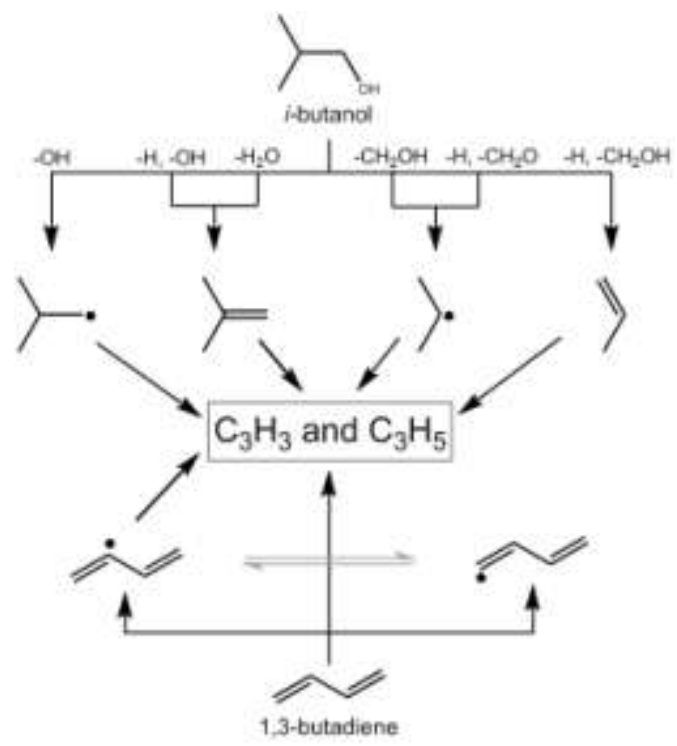

Figure 2: Simplified sketch of the early consumption steps of 1,3-butadiene and $i$-butanol.

It is visualized that $i$-butanol can form $\mathrm{C}_{4} \mathrm{H}_{7}, \mathrm{C}_{4} \mathrm{H}_{8}, \mathrm{C}_{3} \mathrm{H}_{7}$, and $\mathrm{C}_{3} \mathrm{H}_{6}$ intermediates via various $\mathrm{H}$-abstraction and subsequent $\beta$-scission reactions as well as unimolecular decompositions. Further oxidation steps are necessary to form the benzene precursors $\mathrm{C}_{3} \mathrm{H}_{3}$ (propargyl) and $\mathrm{C}_{3} \mathrm{H}_{5}$ (allyl). The same precursors, plus $\mathrm{C}_{4} \mathrm{H}_{5}$ radicals, which are also considered to be important for aromatics formation, are more directly accessible from 1,3-butadiene.

A more detailed analysis of the fuel consumption pathways is provided in Fig. 3 for the flames studied here. For 1,3-butadiene and $i$-butanol, the net rate of production was calculated for a distance from the burner where the molecules are $50 \%$ depleted. Reactions with $\mathrm{H}$ and $\mathrm{OH}$ radicals were found to be the most important initiating reactions for both fuels (Fig. 3), while reactions with $\mathrm{O}$ atoms are of minor importance, especially for the $i$-butanol consumption. 1,3Butadiene is readily converted to $\mathrm{C}_{2}-\mathrm{C}_{4}$ species at the onset of the fuel's oxidation, confirming our simplified sketch (Fig. 2). 

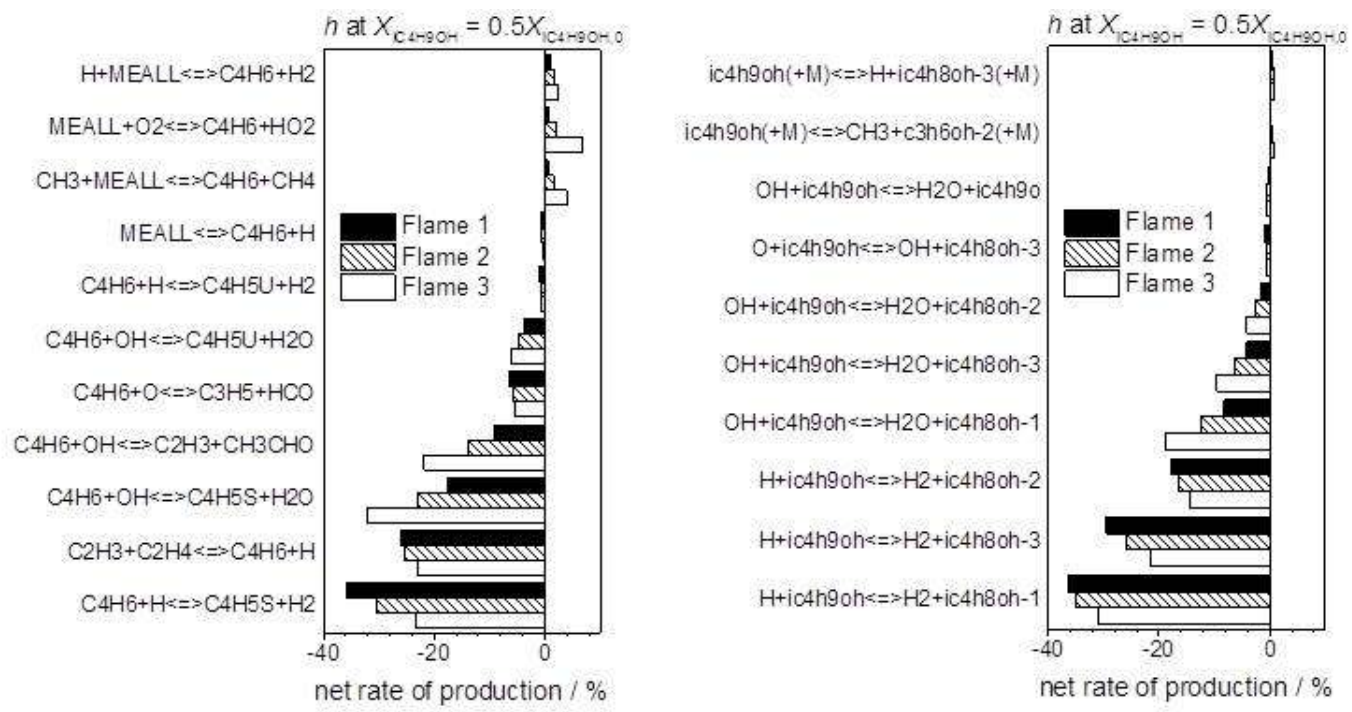

Figure 3: Reaction flux analysis for 1,3-butadiene and $i$-butanol in Flames 1-3.

These various fuel consumption pathways are expected to influence the species intermediate pool of Flames 1-3 and thus, may impact the combustion chemistry. To provide chemically detailed insights into benzene formation in these mixture flames, it is required that the developed mechanism is capable of accurately predicting the intermediates' concentrations, which is shown next.

The reaction model is capable of predicting most $\mathrm{C}_{2}$ hydrocarbons as shown exemplarily for acetylene $\left(\mathrm{C}_{2} \mathrm{H}_{2}\right)$ and ethylene $\left(\mathrm{C}_{2} \mathrm{H}_{4}\right)$ in Fig. 4. For acetylene, the measured concentration profiles are matched within the experimental error limits. For ethylene, a similar level of agreement between measured and calculated profiles is seen. The numerical results show an opposite trend for the peak concentrations of $\mathrm{C}_{2} \mathrm{H}_{2}$ and $\mathrm{C}_{2} \mathrm{H}_{4}$ when comparing Flames 1-3. Such an observation might be extracted also from the experimental data, but is probably hampered by the experimental uncertainties. The increase of the $\mathrm{C}_{2} \mathrm{H}_{4}$ concentration for smaller $1,3-\mathrm{C}_{4} \mathrm{H}_{6} / i$ $\mathrm{C}_{4} \mathrm{H}_{9} \mathrm{OH}$ ratios might be explained by a larger concentration of $\mathrm{CH}_{3}$ and consequently of $\mathrm{C}_{2} \mathrm{H}_{6}$ in Flame 3 compared to Flame 1. The opposite trend for $\mathrm{C}_{2} \mathrm{H}_{2}$ might argue for a fuel-specific 
formation of $\mathrm{C}_{2} \mathrm{H}_{2}$ via 1,3- $\mathrm{C}_{4} \mathrm{H}_{6}+\mathrm{OH}$ (Fig. 3), thus off-setting the oxidation route starting at $\mathrm{C}_{2} \mathrm{H}_{6}$. Additionally, the experimental trend in the peak positions for both $\mathrm{C}_{2} \mathrm{H}_{2}$ and $\mathrm{C}_{2} \mathrm{H}_{4}$ is reproduced by the model calculations. Interestingly, Flame 3, the flame with the largest alcohol content in the fuel mixture, stands off the furthest from the burner surface, indicating differences in the flame speeds of the single fuel components.

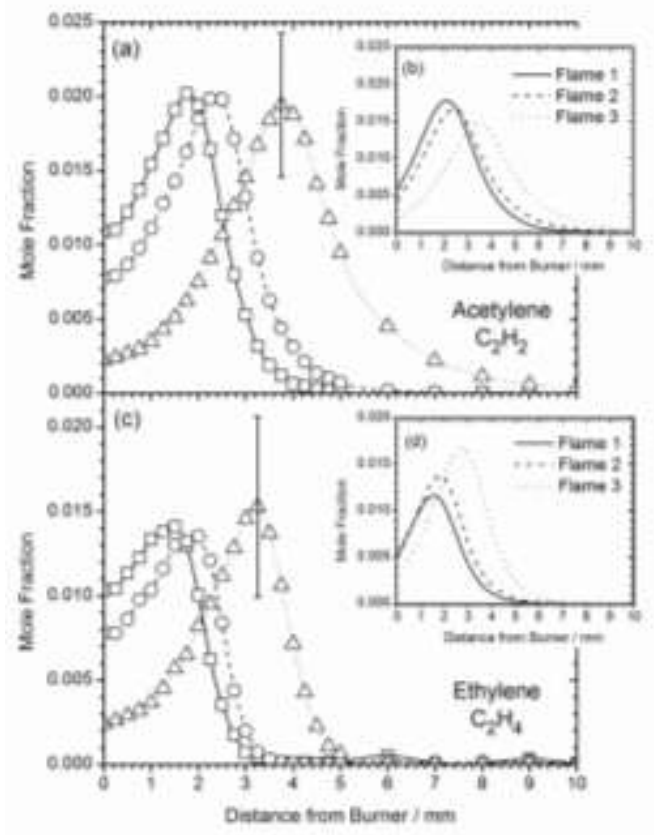

Figure 4: Experimental [(a) and (c)] and modeled [(b) and (d)] mole fraction profiles of $\mathrm{C}_{2} \mathrm{H}_{2}$ and $\mathrm{C}_{2} \mathrm{H}_{4}$ for Flames 1-3. The connected symbols $(\square, \circ$, and $\Delta$ ) represent experimental data for Flames 1-3, respectively. 
The model also predicts the concentrations of $\mathrm{C}_{3}$ species accurately. While the benzene precursors $\mathrm{C}_{3} \mathrm{H}_{3}$ and $\mathrm{C}_{3} \mathrm{H}_{5}$ are discussed later, Fig. 5 shows the comparison between experimental and modeled data for propene $\left(\mathrm{C}_{3} \mathrm{H}_{6}\right)$. The $\mathrm{C}_{3} \mathrm{H}_{6}$ profiles show a clear trend: $A$ larger content of $i$-butanol in the fuel mixture leads to a larger concentration of $\mathrm{C}_{3} \mathrm{H}_{6}$ in the intermediate pool, which is a consequence of the readily formation of $\mathrm{C}_{3} \mathrm{H}_{6}$ in the hightemperature $i$-butanol oxidation as shown Fig. 2. The model accurately predicts the magnitudes, profile shapes, and positions.

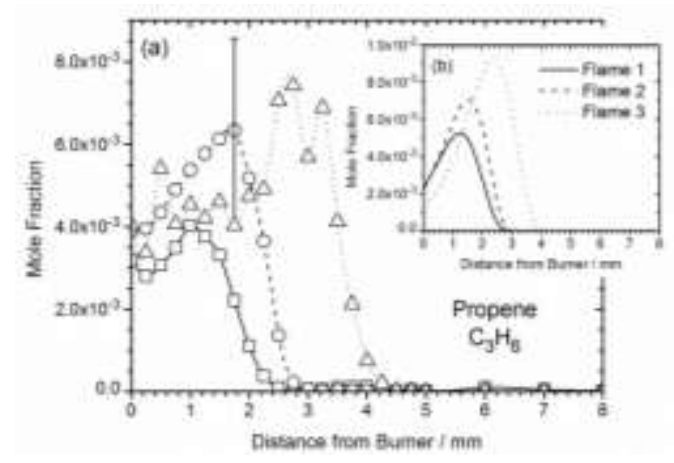

Figure 5: (a) Experimental and (b) modeled mole fraction profiles of $\mathrm{C}_{3} \mathrm{H}_{6}$ (propene) for Flames 1-3. The connected symbols $(\square, \circ$, and $\Delta)$ represent experimental data for Flames 1-3, respectively.

It can be expected that the $\mathrm{C}_{4}$ species pool is largely dependent on the initial concentration of $1,3-\mathrm{C}_{4} \mathrm{H}_{6}$ in the fuel mixture. Concentrations of $\mathrm{C}_{4}$ intermediates, which are provided in the Supplementary Material, are satisfactorily predicted by the current model and show larger concentrations with increasing $1,3-\mathrm{C}_{4} \mathrm{H}_{6} / i-\mathrm{C}_{4} \mathrm{H}_{9} \mathrm{OH}$ ratio. The profiles of the $\mathrm{C}_{4} \mathrm{H}_{5}$ intermediates will be discussed below in context with the benzene formation.

Finally, the model's predictive capabilities are evaluated with respect to key oxygenated intermediates. To exemplify, we present the profiles of formaldehyde $\left(\mathrm{CH}_{2} \mathrm{O}\right)$, ketene $\left(\mathrm{CH}_{2} \mathrm{CO}\right)$, 
and $i$-butanal $\left(i-\mathrm{C}_{4} \mathrm{H}_{8} \mathrm{O}\right)$ in Fig. 6. Concentrations of formaldehyde are predicted accurately with respect to the profile shapes, positions, and the trend between the different flames: the peak mole fraction of $\mathrm{CH}_{2} \mathrm{O}$ increases with increasing $i$-butanol content in the fuel mixture.

Such a clear trend is not obvious when analyzing the experimental ketene mole fraction profiles [Figs. 6(c) and (d)], which is probably a consequence of the $\mathrm{C}_{4} \mathrm{H}_{5}+\mathrm{O}_{2}$ oxidation reactions forming $\mathrm{CH}_{2} \mathrm{CO}+\mathrm{CH}_{2} \mathrm{HCO}$. The model predicts the concentrations correctly; however, the modeled profiles seem to be shifted towards the burner surface when comparing with the experimental data. For $i$-butanal $\left(\mathrm{C}_{4} \mathrm{H}_{8} \mathrm{O}\right)$ [Figs. 6(e) and (f)], both the experimental data and modeling results follow the expected trend: Larger concentrations were observed in Flame 3 than in Flames 1-2 because of the larger $i$-butanol content in the fuel mixture. The model adequately predicts the profile shapes, positions, and peak concentrations.

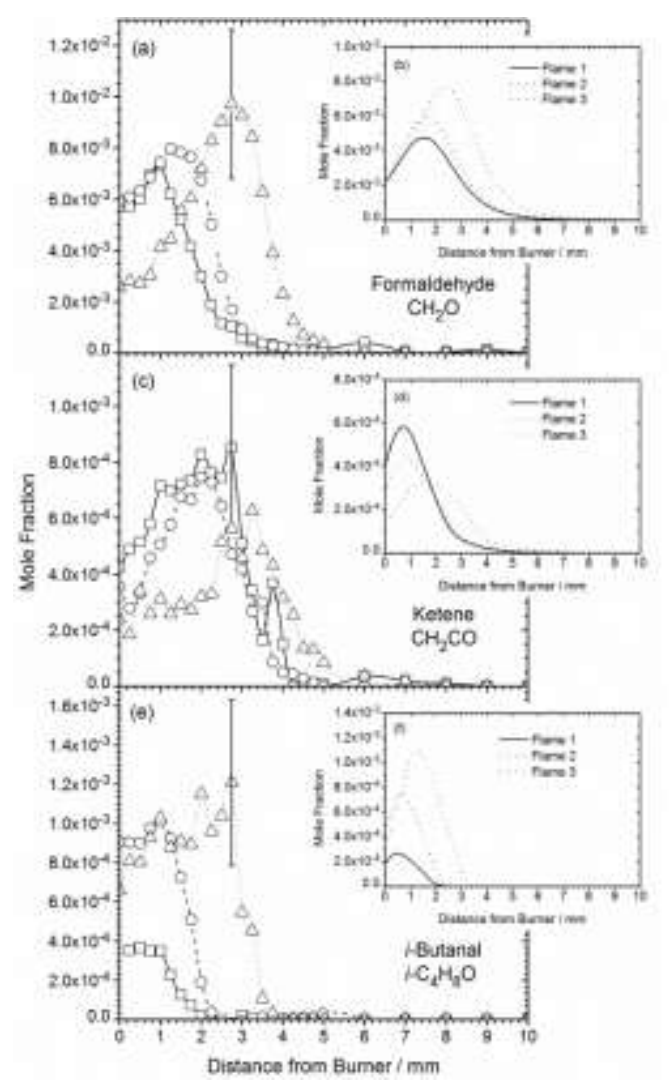


Figure 6: Experimental [(a), (c), and (e)] and modeled [(b), (d), and (f)] mole fraction profiles of $\mathrm{CH}_{2} \mathrm{O}$ (formaldehyde), $\mathrm{C}_{2} \mathrm{H}_{2} \mathrm{O}$ (ketene), and $\mathrm{C}_{4} \mathrm{H}_{8} \mathrm{O}$ (i-butanal) for Flames 1-3. The connected symbols ( $\square$, $\circ$, and $\Delta$ ) represent experimental data for Flames 1-3, respectively.

To summarize: The model is capable of accurately predicting the experimentally measured species profiles for a variety of $\mathrm{C}_{1}-\mathrm{C}_{4}$ and oxygenated species, thus providing detailed insights into the underlying chemistry in these mixture flames. Such a specific description of the base chemistry is a prerequisite to investigate the formation of benzene and its precursors, which will be discussed next.

\subsection{Formation of Benzene and its Precursors}

The involvement of $\mathrm{C}_{3}$ and $\mathrm{C}_{4}$ radicals, i.e. propargyl $\left(\mathrm{C}_{3} \mathrm{H}_{3}\right)$, allyl $\left(\mathrm{C}_{3} \mathrm{H}_{5}\right)$, and $\mathrm{C}_{4} \mathrm{H}_{5}$, in the formation of benzene has been discussed [33]. Following the simplified scheme in Fig. 2, it is expected that these precursors are present in different concentrations in the three mixture flames.

The comparison between the experimentally determined and predicted species profiles is depicted in Fig. 7. For propargyl a clear trend was observed: With a decreasing 1,3- $\mathrm{C}_{4} \mathrm{H}_{6} / i$-butanol ratio less $\mathrm{C}_{3} \mathrm{H}_{3}$ is produced, because less $i-\mathrm{C}_{4} \mathrm{H}_{5}$ reacts with $\mathrm{H}$ to form $\mathrm{C}_{3} \mathrm{H}_{3}+\mathrm{CH}_{3}$ [34]. This trend and the measured propargyl concentrations are very well predicted. For allyl, the dependence of its concentration on the fuel composition is less pronounced, showing even similar peak concentrations in the experimental data. A likely explanation for this observation is the enhanced production of $\mathrm{C}_{3} \mathrm{H}_{6}$ (see Fig. 5) in $i$-butanol combustion. In contrast, the above discussed trend for $\mathrm{C}_{3} \mathrm{H}_{3}$ is based on the formation of $\mathrm{C}_{4} \mathrm{H}_{5}$ and $\mathrm{C}_{3} \mathrm{H}_{3}$ in the chemistry of the 1,3-butadiene component. Concerning $\mathrm{C}_{4} \mathrm{H}_{5}$ radicals, it is obvious that its concentration depends largely on the 1,3-butadiene content in the fuel mixture. Position, shape, and relative 
trends are reproduced by the model calculations; however, predicted species profiles are higher by one order of magnitude. A similar deviation was also observed in the 1,3-butadiene/n-butanol study [8]. It should be kept in mind that (i) the experimental detection might be hampered by probe effects and the lifetimes of the respective cation and that (ii) the model predicts concentrations of $\mathrm{C}_{4} \mathrm{H}_{4}$ (a likely consumption product of $\mathrm{C}_{4} \mathrm{H}_{5}$ ) within the experimental uncertainties.

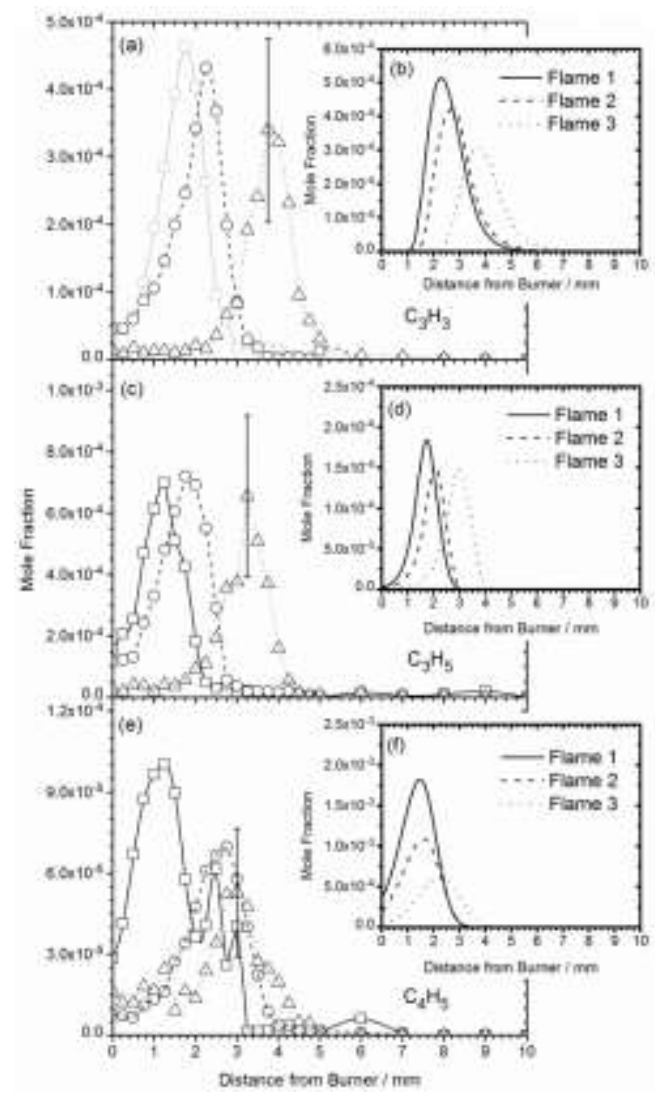

Figure 7: Experimental [(a), (c), and (e)] and modeled [(b), (d), and (f)] mole fraction profiles of $\mathrm{C}_{3} \mathrm{H}_{3}$ (propargyl), $\mathrm{C}_{3} \mathrm{H}_{5}$ (allyl), and $\mathrm{C}_{4} \mathrm{H}_{5}$ for Flames 1-3. The connected symbols ( $\square$, $\circ$, and $\Delta$ ) represent experimental data for Flames $1-3$, respectively. 
The mole fraction profiles of benzene are shown in Fig. 8 together with their modeling results. Levels of benzene are obviously correlated to $\mathrm{C}_{3} \mathrm{H}_{3}$ and $\mathrm{C}_{4} \mathrm{H}_{5}$ concentrations and, following the above discussion, to the initial 1,3-butadiene percentage in the fuel mixture. Similar to the earlier work [8], it is seen that the concentration of benzene is not correlated to the stoichiometry of the flames.

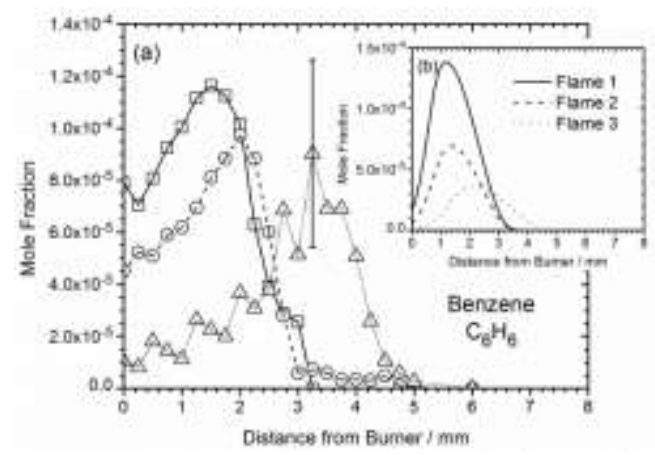

Figure 8: Experimental (a) and modeled (b) mole fractions of benzene as function of the distance from the burner. The connected symbols ( $\square, \circ$, and $\Delta$ ) represent experimental data for Flames 1-3, respectively.

While the differences between the observed peak concentrations of benzene in Flames 2 and 3 compared to the equivalent 1,3-butadiene/n-butanol flames from Ref. [8] are not significant, we observe larger benzene levels in the 1,3-butadiene/i-butanol $(25 \% / 75 \%)$ flame compared with the 1,3-butadiene/n-butanol (25\%/75\%) flame. This difference is caused by the different chemistry of the alcohol components, specifically the enhanced tendency to form $\mathrm{C}_{3}$ intermediates in $i$-butanol compared to $n$-butanol flames. This fact was also observed in the work of Oßwald et al. [32], who also measured larger benzene concentrations in $i$-butanol compared to n-butanol flames. 
More detailed insights into benzene formation are revealed by reaction flux analyses as summarized in Fig. 9. They reveal that in all three flames benzene is formed via $\mathrm{H}$-assisted isomerization from a linear and the fulvene $\mathrm{C}_{6} \mathrm{H}_{6}$ isomers. Further contributions arise from $\mathrm{C}_{3} \mathrm{H}_{3}+\mathrm{C}_{3} \mathrm{H}_{3}$, phenyl+H, and the $\mathrm{C}_{4} \mathrm{H}_{5}+\mathrm{C}_{2} \mathrm{H}_{2}$ chemistry. No significant differences of their importance were observed for the three mixture flames. Only for benzene oxidation reactions, a dependency on the intermediate pool composition is slightly visible.

Note that the benzene concentration was found to be affected by the particular rate coefficient of the $\mathrm{H}$-assisted benzene-fulvene isomerization. The fulvene chemistry, shown earlier to affect the benzene formation [10, 27, 31], was newly implemented in the model. According to the flux analyses, fulvene is almost exclusively formed through the propargyl recombination and the $\mathrm{C}_{4} \mathrm{H}_{5}+\mathrm{C}_{2} \mathrm{H}_{2}$ reactions and consumed mostly by the rearrangement to benzene.
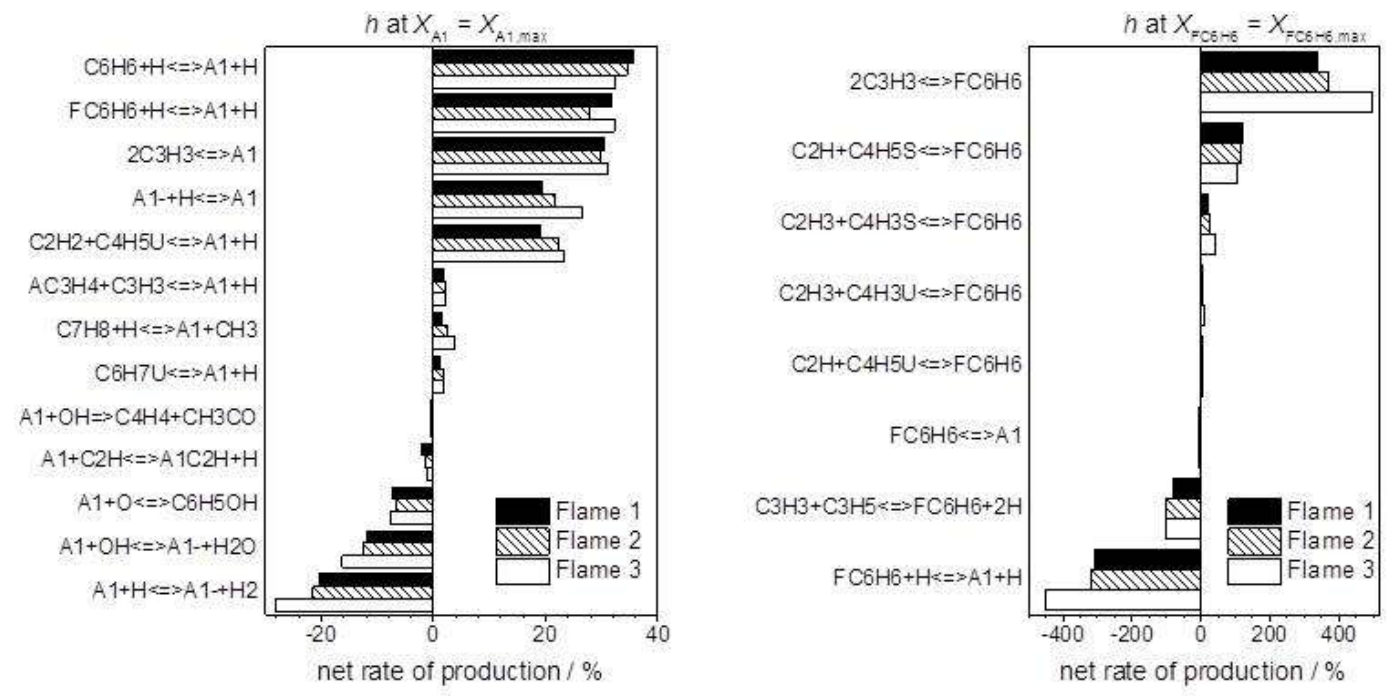

Figure 9: Reaction flux analysis calculated for benzene (A1) and fulvene $\left(\mathrm{FC}_{6} \mathrm{H}_{6}\right)$ for Flames 1-3. 
The identification of $\mathrm{H}$-initiated isomerization reactions between three $\mathrm{C}_{6} \mathrm{H}_{6}$ molecules (benzene, fulvene, and a $\mathrm{C}_{6} \mathrm{H}_{6}$ linear structure) reveals the need to study in more detail the chemistry of the linear $\mathrm{C}_{6} \mathrm{H}_{6}$ isomer, which was already suggested by Scherer et al. [35] to play an important role.

\section{Summary and Conclusions}

The chemical structure of three low-pressure premixed flames fueled by mixtures of 1,3-butadiene/i-butanol of various ratios were analyzed experimentally using flame-sampling molecular-beam mass spectrometry and numerically using a newly updated detailed chemistry model. Trends in peak concentrations of $\mathrm{C}_{2}-\mathrm{C}_{4}$ and oxygenated intermediates were correlated to the fuel composition. A particular emphasis was on how the fuel mixture influences the formation of benzene and its precursors.

Both, experimental and modeling results suggest that benzene formation can be linked mostly to the initial concentration of 1,3-butadiene. Its early consumption products, i.e., the $\mathrm{C}_{4} \mathrm{H}_{5}$ radicals, which in a subsequent reaction can also be converted to propargyl, dominate the benzene formation. Replacing 1,3-butadiene with $i$-butanol leads to smaller concentrations of $\mathrm{C}_{4} \mathrm{H}_{5}$ and $\mathrm{C}_{3} \mathrm{H}_{3}$, and thus to lower benzene concentrations. The allyl radical, which is a preferably formed benzene precursor in $i$-butanol combustion, was found to be of minor importance. As a consequence, benzene mole fractions are not related to the flames' stoichiometry as one might have expected. That is, Flame 3, the richest of the flames studied here, produced the smallest amount of benzene because of the largest $i$-butanol content in the fuel mixture. 
Because of the observed dominance of the $\mathrm{C}_{4} \mathrm{H}_{5}$ chemistry, a strong cross-linkage between the component's individual species pools is not observable with regard to the formation of benzene and its precursors. With respect to this aspect, the 1,3-butadiene/i-butanol flames studied here behave similarly as the 1,3-butadiene/n-butanol mixture flames. As a summary, these mixture flames can be successfully modeled when the combustion chemistry of the individual components are well known.

\section{Acknowledgments}

The work is supported by the DAAD (Deutscher Akademischer Austausch Dienst) under Grant No. 56025647. MBU and TM are grateful to the assistance of M. Dietrich and S. Riebl. NH and KM are supported by the U.S. Department of Energy (USDOE), Office of Basic Energy Sciences (BES) under Grand No. DE-AC04-94-AL85000. BY is supported by National Science Foundation of China (91541113 and U1332208). The measurements were performed within the "Flame Team" collaboration at the Advanced Light Source (ALS), Lawrence Berkeley National Laboratory, Berkeley, USA. The experiments have profited from the expert technical assistance of Paul Fugazzi. The Advanced Light Source is supported by the Director, Office of Science, BES, USDOE under Contract No. DE-AC02-05CH11231. Sandia is a multi-program laboratory operated by Sandia Corporation, a Lockheed Martin Company, for the National Nuclear Security Administration under contract DE-AC04-94-AL85000. 


\section{References:}

[1] K. Kohse-Höinghaus, P. Oßwald, T. A. Cool, T. Kasper, N. Hansen, F. Qi, C. K. Westbrook, P. R. Westmoreland, Angew. Chem. Int. Ed. 49 (21) (2010) 3572-3597.

[2] S. M. Sarathy, P. Oßwald, N. Hansen, K. Kohse-Höinghaus, Progr. Energy Combust. Sci. 44 (2014) 40-102.

[3] M. Köhler, T. Kathrotia, P. Oßwald, M. L. Fischer-Tammer, K. Mosharnmer, U. Riedel, Combust. Flame 162 (9) (2015) 3197-3209.

[4] Q. Q. Li, C. L. Tang, Y. Cheng, L. Guan, Z. H. Huang, Energy Fuels 29 (8) (2015) 53345348.

[5] Z. Serinyel, C. Togbe, G. Dayma, P. Dagaut, Combust. Flame 161 (12) (2014) 30033013.

[6] G. Wang, W. H. Yuan, Y. Y. Li, L. Zhao, F. Qi, Combust. Flame 162 (9) (2015) 32773287.

[7] K. Moshammer, L. Seidel, Y. Wang, H. Selim, S. M. Sarathy, F. Mauss, N. Hansen, Proc. Combust. Inst. submitted (2016).

[8] N. Hansen, M. Braun-Unkhoff, T. Kathrotia, A. Lucassen, B. Yang, Proc. Combust. Inst. 35 (2015) 771-778.

[9] J. P. Senosiain, J. A. Miller, J. Phys. Chem. A. 111 (19) (2007) 3740-3747.

[10] N. Hansen, W. Li, M. E. Law, T. Kasper, P. R. Westmoreland, B. Yang, T. A. Cool, A. Lucassen, Phys. Chem. Chem. Phys. 12 (38) (2010) 12112-12122.

[11] G. Black, H. J. Curran, S. Pichon, J. M. Simmie, V. Zhukov, Combust. Flame 157 (2) (2010) 363-373.

[12] J. M. Simmie, H. J. Curran, J. Phys. Chem. A. 113 (27) (2009) 7834-7845. 
[13] T. A. Cool, A. McIlroy, F. Qi, P. R. Westmoreland, L. Poisson, D. S. Peterka, M. Ahmed, Rev. Sci. Instr. 76 (9) (2005).

[14] N. Hansen, T. A. Cool, P. R. Westmoreland, K. Kohse-Höinghaus, Progr. Energy Combust. Sci. 35 (2) (2009) 168-191.

[15] F. N. Egolfopoulos, N. Hansen, Y. Ju, K. Kohse-Höinghaus, C. K. Law, F. Qi, Progr. Energy Combust. Sci. 43 (2014) 36-67.

[16] S. R. Leone, M. Ahmed, K. R. Wilson, Phys. Chem. Chem. Phys. 12 (25) (2010) 65646578.

[17] F. Qi, Proc. Combust. Inst. 34 (2013) 33-63.

[18] P. Oßwald, U. Struckmeier, T. Kasper, K. Kohse-Höinghaus, J. Wang, T. A. Cool, N. Hansen, P. R. Westmoreland, J. Phys. Chem. A. 111 (19) (2007) 4093-4101.

[19] Photonionization Cross Section Database, http://flame.nsrl.ustc.edu.cn/database/.

[20] N. Hansen, M. R. Harper, W. H. Green, Phys. Chem. Chem. Phys. 13 (45) (2011) 2026220274.

[21] S. Dooley, F. L. Dryer, B. Yang, J. Wang, T. A. Cool, T. Kasper, N. Hansen, Combust. Flame 158 (4) (2011) 732-741.

[22] M. Kamphus, M. Braun-Unkhoff, K. Kohse-Höinghaus, Combust. Flame 152 (1-2) (2008) 28-59.

[23] M. Köhler, A. Brockhinke, M. Braun-Unkhoff, K. Kohse-Höinghaus, J. Phys. Chem. A 114 (14) (2010) 4719-4734.

[24] H. Böhm, M. Braun-Unkhoff, Combust. Flame 153 (2008) 84-96.

[25] H. Böhm, M. Braun-Unkhoff, P. Frank, Prog. Comput. Fluid Dyn. 3 (2003) 145-150.

[26] S. Peukert, C. Naumann, M. Braun-Unkhoff, Z. Phys. Chem. 223 (4-5) (2009) 427-446. 
[27] A. Nawdiyal, N. Hansen, T. Zeuch, L. Seidel, F. Mauss, Proc. Combust. Inst. 35 (2015) $325-332$.

[28] D.G. Goodwin, H.K. Moffat, R.L. Speth, 2015 Cantera: An object-oriented software toolkit for chemical kinetics, thermodynamics, and transport processes, http://www.cantera.org, Version 2.2.0.

[29] R.J. Kee, G. Dixon-Lewis, J. Warnatz, M.E. Coltrin, J. A. Miller, 1986, The Chemkin Transport Database. Report SAND86-8246, Sandia National Laboratories, Livermore, CA, USA.

[30] E. Goos, A. Burcat, B. Ruscic, Extended Third Millennium Ideal Gas and Condensed Phase Thermochemical Database for Combustion with updates from Active Thermochemical Tables, http://burcat.technion.ac.il/dir/.

[31] N. Hansen, J. A. Miller, T. Kasper, K. Kohse-Höinghaus, P. R. Westmoreland, J. Wang, T. A. Cool, Proc. Combust. Inst. 32 (2009) 623-630.

[32] P. Oßwald, H. Güldenberg, K. Kohse-Höinghaus, B. Yang, T. Yuan, F. Qi, Combust. Flame 158 (1) (2011) 2-15.

[33] J.A. Miller, M.J. Pilling, J. Troe, Proc. Combust. Inst. 30 (1) (2005) 43-88.

[34] L. B. Harding, S. J. Klippenstein, Y. Georgievskii, J. Phys. Chem. A 111 (19) (2007) 3789-3801.

[35] S. Scherer, Th. Just, P. Frank, Proc. Combust. Inst. 28 (2) (2000) 1511-1518. 


\section{List of Figures Captions}

\section{Figure 1:}

Mole fraction profiles of the main species $\left(\mathrm{H}_{2}, \mathrm{H}_{2} \mathrm{O}, \mathrm{CO}, \mathrm{O}_{2}, \mathrm{Ar}, \mathrm{CO}_{2}, 1,3-\mathrm{C}_{4} \mathrm{H}_{6}\right.$, and $\left.i-\mathrm{C}_{4} \mathrm{H}_{9} \mathrm{OH}\right)$ as function of the distance from the burner. Experimental data are shown as symbols and model results as lines.

\section{Figure 2:}

Simplified sketch of the early consumption steps of 1,3-butadiene and $i$-butanol.

\section{Figure 3:}

Reaction flux analysis for 1,3-butadiene and $i$-butanol in Flames 1-3.

\section{Figure 4:}

Experimental [(a) and (c)] and modeled [(b) and (d)] mole fraction profiles of $\mathrm{C}_{2} \mathrm{H}_{2}$ and $\mathrm{C}_{2} \mathrm{H}_{4}$ for Flames 1-3. The connected symbols ( $\square, \circ$, and $\Delta$ ) represent experimental data for Flames 1-3, respectively.

\section{Figure 5:}

(a) Experimental and (b) modeled mole fraction profiles of $\mathrm{C}_{3} \mathrm{H}_{6}$ (propene) for Flames 1-3. The connected symbols ( $\square, \circ$, and $\Delta$ ) represent experimental data for Flames 1-3, respectively.

\section{Figure 6:}


Experimental [(a), (c), and (e)] and modeled [(b), (d), and (f)] mole fraction profiles of $\mathrm{CH}_{2} \mathrm{O}$ (formaldehyde), $\mathrm{C}_{2} \mathrm{H}_{2} \mathrm{O}$ (ketene), and $\mathrm{C}_{4} \mathrm{H}_{8} \mathrm{O}$ (i-butanal) for Flames 1-3. The connected symbols $(\square, \circ$, and $\Delta)$ represent experimental data for Flames 1-3, respectively.

\section{Figure 7:}

Experimental [(a), (c), and (e)] and modeled [(b), (d), and (f)] mole fraction profiles of $\mathrm{C}_{3} \mathrm{H}_{3}$ (propargyl), $\mathrm{C}_{3} \mathrm{H}_{5}$ (allyl), and $\mathrm{C}_{4} \mathrm{H}_{5}$ for Flames 1-3. The connected symbols ( $\square$, $\circ$, and $\Delta$ ) represent experimental data for Flames 1-3, respectively.

\section{Figure 8:}

Experimental (a) and modeled (b) mole fractions of benzene as function of the distance from the burner. The connected symbols $(\square, \circ$, and $\Delta)$ represent experimental data for Flames 1-3, respectively.

Figure 9: Reaction flux analysis calculated for benzene (A1) and fulvene $\left(\mathrm{FC}_{6} \mathrm{H}_{6}\right)$ for Flames 13. 